
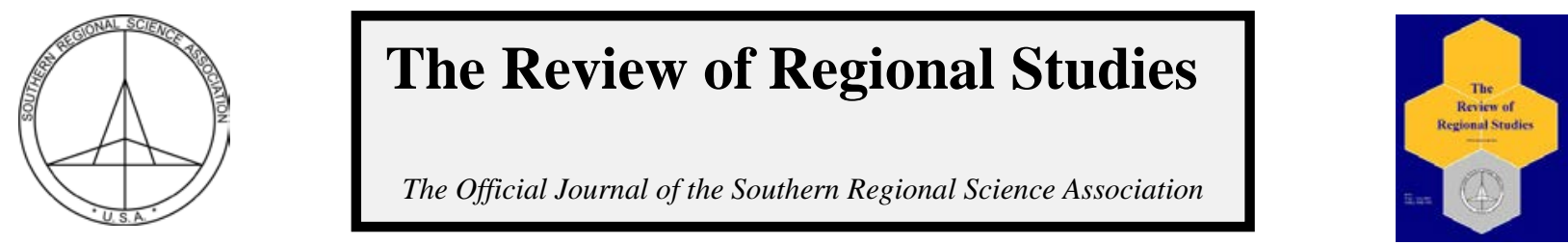

\title{
Looking Behind the Scenes: An Assessment of the Interdependence of Brazilian Cultural Industries*
}

\author{
Amir B. Ferreira Neto ${ }^{\mathrm{a}}$, Fernando S. Perobelli ${ }^{\mathrm{b}}$, and Alexandre Rabelo ${ }^{\mathrm{b}}$ \\ ${ }^{a}$ Department of Economics, West Virginia University, USA \\ ${ }^{b}$ Department of Economics, Universidade Federal de Juiz de Fora, Brazil
}

\begin{abstract}
In this paper, we examine the increasing relative importance of the cultural sector in the Brazilian economy. Specifically, we look at the integration of the cultural sector production structure into Brazil's production structure. We contribute to the literature by making a systematic evaluation of the production integration of the cultural sector into the Brazilian production structure. To do so, we disaggregate the cultural economic sectors using Brazilian inputoutput tables for 2005 and 2009. Using both tables, we calculate different measures of linkages and use the Structural Decomposition Analysis (SDA). Our results show transition in relative importance from manufacturing to services for the cultural sectors and that investments in cultural activities can produce positive results for the Brazilian economy in terms of income and employment effects.
\end{abstract}

Keywords: Brazil, cultural industries, input-output tables, interdependence analysis.

JEL Codes: Z10, Z19, D5

\section{INTRODUCTION}

Cultural economics is broadly-defined and there has been a lack of agreement on its primary focus. As pointed out by Blaug (2001) and Towse (2003), studies of the arts were the main interest in the beginning (1960s); however, there is an increasing number of studies that deal with other aspects of cultural activities, such as demand and supply of cultural goods, labor market of artists, and public subsidies, among others. The cultural economics topic has gained more attention in recent years, and we can observe supranational institutions such as UNESCO, OECD, Eurostat and the World Bank, for example, that have statistics on cultural activities.

In this paper, we examine the increasing relative importance of the cultural sector in the Brazilian economy. This is important given that there has been a lack of studies dealing with the production structure of cultural activities, specially focusing on developing countries. So far, the studies looking at the cultural sector performed only an impact analysis of this sector in the economy and overlooked the spillover effects from the production process. Thus, the objective of this paper is to take the studies a step further and shed some light on the integration of the cultural sector production structure into the country's production structure. To accomplish this, we evaluate

\footnotetext{
* Acknowledgements. We would like to thank the anonymous referees and the editor of this journal for their comments which helped to improve the manuscript. Also, we benefited from the help with editing from Izabella Barbosa and Caigan Mackenzie. The remaining errors are our own. Perobelli thanks CNPq and FAPEMIG for financial support during this research.

Ferreira Neto is a PhD Candidate in Economics at West Virginia University. Perobelli is a Full Professor of Economics at the Universidade Federal de Juiz de Fora, Brazil and Rabelo is a graduate student in Economics at Universidade Federal de Juiz de Fora, Brazil. Corresponding Author: A Ferreira Neto E-mail: amneto@mix.wvu.edu
}

(C) Southern Regional Science Association 2018.

ISSN 1553-0892, 0048-749X (online)

www.srsa.org/rrs 
the interdependence of the cultural sector in the Brazilian production structure by describing and mapping the cultural sector's production links to the other sectors in the Brazilian economy. Moreover, we investigate the evolution of this sector in the production structure by incorporating the temporal aspect.

The Brazilian cultural industry is a fast-growing part of the country's economy, thereby warranting additional study by academic researchers. As per data from CEMPRE ${ }^{1}$ and PNAD, ${ }^{2}$ the Instituto Brasileiro de Geografia e Estatística (IBGE) reported some statistics on cultural industries for two periods, the first from 2003 to 2005 and the second from 2007 to 2010. For the former, the report shows a 32 percent growth in gross output, 32.5 percent growth in value added, 19 percent growth in the number of enterprises, and 32 percent growth in government expenditure. As for the latter, the report points to a 31 percent growth in gross output, 38 percent growth in value added, 9 percent growth in the number of enterprises, and 64 percent growth in government expenditure. Moreover, the number of formal workers grew 13 percent in both periods from 2003 to 2005 and from 2007 to 2010, according to CEMPRE; however, the number of formal and informal workers decreased by 11 percent according to PNAD. Ergo, unlike Di Moto and Merk (1993) suggest in the case of Idaho, the cultural sector in Brazil is not behaving as a mature industry but rather as a growing one.

According to Mellander (2009), sectors with a high concentration of creativity in the labor force are included in the concept of cultural or creative industry. On the other hand, Markusen et al. (2008) define cultural industries as those that produce cultural goods and services, including television, radio, cinema, newspapers, magazine and book publishing, music recording, advertising, and the performing arts. Although some related sectors, such as education, are not usually included in the cultural industry, Markusen et al. (2008) highlight that if the aim is to study the impact of a sector in the economy, it is important to incorporate the entire supply chain into the cultural industry definition to better analyze the connections between the supplier and the distributor sectors. Thus, we define cultural sectors as the industries that are directly or indirectly connected to those that create, produce, or distribute goods and services that have creativity as its main input. This definition ${ }^{3}$ is similar to the one used by IBGE (2013), which is based on the United Nations Educational, Scientific, and Cultural Organization (UNESCO) that has been adopted by several countries and agencies.

Throsby (2004) stresses the importance of conducting additional impact analysis of cultural activities in the broader sectorial sense rather than the impact of a festival or a museum, for example, which are more commonly studied in cultural economics. The author states that analytical methods, such as input-output, social accounting matrix, and computable general equilibrium methods, are extremely important for gaining a better understanding of the impact of these industries and on these industries, but this is rare because of a lack of data. Some of the pioneering works using input-output analysis to assess cultural activities are the works of Vaughan (1984) and the National Endowment for the Arts (NEA, 1986). Vaughan (1984) combined the United Kingdom (UK) input-output table with results of a survey he conducted and analyzed the

\footnotetext{
${ }^{1}$ CEMPRE - Cadastro Central de Empresas by IBGE (Brazilian Institute of Geography and Statistics) is the Brazilian register of enterprises recorded by IBGE.

${ }^{2}$ PNAD - Pesquisa Nacional por Amostra de Domicílios - is the Brazilian Household Survey conducted by IBGE

${ }^{3}$ Notice that the cultural definition as described can be related to either the industry or the occupation in which the activity is taking place. For instance, a jeweler is considered an artist; therefore, this portion of the jewelry industry is considered a cultural industry. Similarly, because radio and TV need equipment to broadcast, the manufacture of such equipment is an indirect cultural industry.
}

(c) Southern Regional Science Association 2018. 
impact of tourism in the UK. The NEA (1986) report showed the cultural activities' numbers, such as gross output, value added and others in the 1984 input-output data in the United States.

More recently, Di Moto and Merk (1993) analyzed the impact of arts activities in Idaho on the local economy; Gazel and Schwer (1997) assessed the income and employment impacts of the Grateful Dead performance in Las Vegas. Bryan et al. (2000) evaluated the economic impacts of cultural activities in the Welsh economy, and Llop and Arauzo-Carod (2012) studied the impact of the Gaudí Centre museum in Cataluña. One important development in this area was the U.S. Arts and Cultural Production Satellite Account released by the NEA and the Bureau of Economic Analysis (BEA) in 2015. This satellite account provides researchers and policymakers with refined data on cultural activities, helping them to better understand this sector.

For Brazil, ${ }^{4}$ most of the previous studies have focused on topics such as the cultural labor market, ${ }^{5}$ the consumption of cultural goods, ${ }^{6}$ and cultural agglomeration. ${ }^{7}$ Although these topics are important, the "chain effect" noted by Bille and Schulze (2006) and Markusen (2007) is a key aspect to understanding the contribution of cultural activities to regional development. There are three works that we are aware of that use general equilibrium analysis to assess the impact of cultural activities in the economy. The earliest work was done by Porsse et al. (2009) which evaluated the economic impacts of the Natal Luz festival in Brazil's Rio Grande do Sul state using both surveys and input-output techniques. The authors concluded that the festival had a large impact on the overall indices, and the main reason for this effect was the attraction of tourists. David and Guilhoto (2012) studied the cultural sectors in the Brazilian input-output table for 2006 and found that the employment and wage multipliers for cultural sectors are above the Brazilian average. More recently, Souza et al. (2016) investigated the impact of "Vale Cultura," a federal government program that provides a personal and nontransferable voucher to eligible households - employees of participating firms who have a monthly income under five minimum wages - to buy cultural products. According to the authors, this policy has had a positive impact not only on the cultural sector but also had a positive indirect effect on related sectors.

We contribute to the literature by making a systematic evaluation of the production integration of the cultural sector into the Brazilian production structure. This type of analysis is especially important for developing countries, such as Brazil, because the cultural sector can increase income and create jobs. Therefore, understanding how the cultural sector is inserted into the Brazilian production structure is important for policymakers and private agents. Such analysis can explain how specific policies and actions directly and indirectly impact the economy. Thus, policymakers and private agents can understand how to increase the positive income and employment effects from the cultural sector.

To evaluate the integration of the cultural sectors into the Brazilian production structure, we disaggregate the cultural economic sectors using Brazilian input-output tables for 2005 and 2009. Using both tables, we calculate different measures of linkages and make use of the Structural Decomposition Analysis (SDA). It is important to stress that this work differentiates itself from

\footnotetext{
${ }^{4}$ There are several studies showing the positive impact of the cultural industries across the world, other than those cited above. A non-exhaustive list includes: Dolfman et al. (2007), UNESCO (2012), NEA (2015), Cebr (2015), and NEA (2016).

${ }^{5}$ See Silva et al. (2007), Ferreira Neto, Freguglia, and Fajardo (2012), and Machado, Rabelo, and Moreira (2013)

${ }^{6}$ See Diniz and Machado (2011), Earp (2009), Machado, Menezes, and Diniz (2010), Bertini (2008), Reis (2002, 2006), and Valiati and Florissi (2007).

${ }^{7}$ See Golgher (2011), Machado, Diniz, and Simões (2013), and Ferreira Neto and Perobelli (2013).
}

(C) Southern Regional Science Association 2018. 
David and Guilhoto (2012) by: i) adding the time effect, that is, by looking at two time periods and using SDA to derive the drivers of the change between the two years; ii) using the hypothetical extraction analysis, which complements the other linkage indices by mapping the sectors most impacted by the cultural industries; and iii) by how we calculate the cultural sectors in the Brazilian production structure. While we consider 13 industries in our analysis, they restrict theirs to 11 industries causing them to miss important industries such as trade and education. Moreover, they use full industry information while we disaggregate the cultural content of each industry considered.

The remainder of the paper is as follows: Section 2 presents a brief overview of the Brazilian cultural industries over the last few years, Section 3 describes the data used and its manipulation, Section 4 presents the methodologies used and their results, and Section 5 lays out our conclusions.

\section{FEATURES OF BRAZILIAN CULTURAL INDUSTRY}

In this section, we present an overview of the cultural industries in Brazil. This overview illustrates the relative importance of the cultural sector in Brazil and how it has been changing over the past few years. The Brazilian Institute of Geography and Statistics (IBGE) periodically releases reports on several Brazilian industries that include information gathered annually on both consumption and production of goods and services. For instance, IBGE reports the number of workers and firms, government expenditures, wages, revenues, output, and household expenditures, among others. For the cultural industry, the most recent report is the Sistema de Informações e Indicadores Culturais 2007-2010.

Table 1 presents summary information on accounts included in the input-output tables, such as gross output, value added, and final demand by the government. In general, the cultural share for such accounts are almost constant over time. For example, the cultural share of gross output represents around 11 percent of the Brazilian total gross output; in terms of value added, the cultural share is 12 percent of total value added; and with respect to government expenditures, the cultural share is around 0.3 percent of total government expenditures.

Because Brazil is a continental-sized country, it is interesting to have a picture of the cultural activities in the country by regions. Figure 1 shows a map of the five Brazilian regions: North, Northeast, Southeast, South, and Center-West. Table 2 illustrates the yearly per capita expenditures on culture activities by summing all levels of governments, i.e., municipal, state, and federal, as well as the state government expenditure on culture by Brazilian macro-regions shown above. The national per capita expenditures, as well as state expenditures, increased between 2007 and 2010, the former by 58.5 percent and the latter by 77.5 percent. For the national per capita expenditures, the North region had the smallest increase (22.5 percent) while the Center-West had

Table 1 - Cultural Industry in Brazil

\begin{tabular}{c|ccccccccc}
\hline \hline Year & \multicolumn{3}{|c}{ Gross Output* } & \multicolumn{3}{c}{ Value Added* } & \multicolumn{3}{c}{ Government Expense* } \\
& Total & Cultural & $\%$ & Total & Cultural & $\%$ & Total & Cultural & $\%$ \\
\hline 2007 & $2,219.6$ & 250.9 & 11.30 & 898.4 & 111.0 & 12.35 & $1,761.0$ & 4.5 & 0.25 \\
2008 & $2,608.0$ & 281.3 & 10.79 & $1,064.2$ & 123.8 & 11.64 & $1,906.2$ & 5.6 & 0.29 \\
2009 & $2,596.2$ & 287.7 & 11.08 & $1,123.2$ & 128.1 & 11.40 & $2,115.6$ & 6.2 & 0.29 \\
2010 & $3,048.5$ & 328.9 & 10.79 & $1,341.8$ & 152.9 & 11.39 & $2,303.8$ & 7.3 & 0.31 \\
\hline \hline
\end{tabular}

Source: IBGE: Sistema de Informações e Indicadores Culturais 2007-2010. *In R\$1,000,000,000.00.

(C) Southern Regional Science Association 2018. 


\section{Figure 1 - Brazil's Macro-regions}

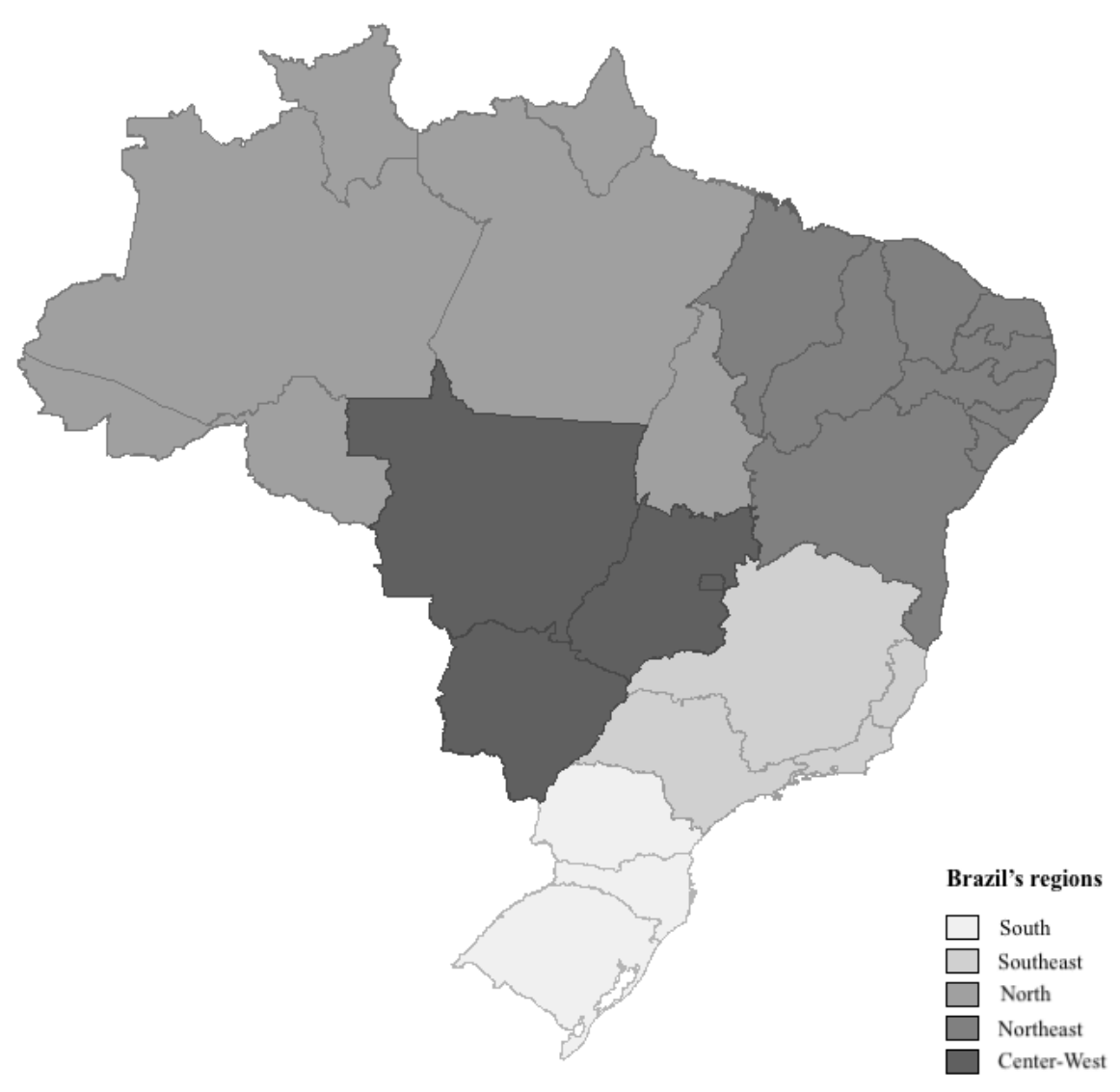

Source: IBGE.

the largest increase (66.8 percent). However, in absolute terms, the South region is where the governments as a whole spent less per person on cultural goods and services, $\mathrm{R} \$ 22.50$ as of 2010, and the Center-West is where the governments spent the most, $\mathrm{R} \$ 90.74$. As for state expenditures, the Northeastern and the Center-West regions show levels of increases similar to the national level,

Table 2: Per Capita and State Government Expenditure on Culture by Macro-region

\begin{tabular}{l|ccccccc}
\hline \hline \multirow{2}{*}{ Region } & \multicolumn{3}{|c}{ Per Capita Expenditure (R\$) } & \multicolumn{4}{c}{ State Expenditure* } \\
& 2007 & 2010 & \% diff. & 2007 & 2010 & \% diff. & \% of 2010 \\
\hline Brazil & 24.00 & 38.04 & 58.5 & $1,426,783$ & $2,532,673$ & 77.5 & $100 \%$ \\
North & 21.96 & 26.90 & 22.5 & 204,180 & 257,940 & 26.3 & $10.2 \%$ \\
Northeast & 17.34 & 27.63 & 59.3 & 299,708 & 519,932 & 73.5 & $20.5 \%$ \\
Southeast & 25.95 & 43.20 & 66.5 & 642,102 & $1,351,046$ & 10.4 & $53.3 \%$ \\
South & 17.25 & 22.50 & 30.4 & 159,348 & 196,776 & 23.5 & $7.8 \%$ \\
Center-West & 54.40 & 90.74 & 66.8 & 121,445 & 206,979 & 70.4 & $8.2 \%$ \\
\hline \hline
\end{tabular}

Source: IBGE: Sistema de Informações e Indicadores Culturais 2007-2010. *In R\$1,000,000.00.

(C) Southern Regional Science Association 2018. 
Table 3: Number of Workers and Mean Income by Macro-region

\begin{tabular}{r|cccccccc}
\hline \hline \multirow{2}{*}{ Region } & \multicolumn{3}{|c}{ Number of Workers* } & \multicolumn{4}{c}{ Average Income (R\$) } \\
& \multicolumn{3}{|c}{ Total } & \multicolumn{2}{c}{ Culture } & \multicolumn{3}{c}{ Total } \\
Culture \\
& 2007 & 2011 & 2007 & 2011 & 2007 & 2011 & 2007 & 2011 \\
\hline Brazil & 89,928 & 93,493 & 4,177 & 3,718 & 1,213 & 1,375 & 1,258 & 1,463 \\
North & 6,808 & 7,393 & 188 & 201 & 994 & 1,123 & 975 & 1,028 \\
Northeast & 23,687 & 23,727 & 920 & 762 & 760 & 918 & 750 & 851 \\
Southeast & 38,178 & 40,298 & 2,105 & 1,873 & 1,400 & 1,562 & 1,518 & 1,739 \\
South & 14,470 & 14,749 & 675 & 641 & 1,353 & 1,492 & 1,187 & 1,438 \\
Center-West & 6,784 & 7,327 & 289 & 240 & 1,455 & 1,665 & 1,346 & 1,687 \\
\hline \hline
\end{tabular}

Source: IBGE: Sistema de Informações e Indicadores Culturais 2007-2010.

73.5 percent and 70.4 percent, respectively. However, the Southeast region is still the one that spends the most on culture, representing 53.3 percent of the national expenditure.

Table 3 contains information regarding labor force participation, such as the number of employed workers and average income levels by Brazilian macro-region. Tables 1 and 2 show that the cultural industry in Brazil is producing more (both in terms of gross output and value added), and the government is investing more (both at the national and state levels). However, during 2007 and 2011, there was a decline in the number of workers in the cultural industry in almost every region except the North region. On the other hand, the average income, both overall and in only the cultural industries, increased over this period everywhere.

\section{DATA}

\subsection{Input-output model}

The input-output matrix describes the intersectoral flows in an economy used to analyze the industrial interdependence in an economy (Miller and Blair, 2009). Let the following equation represent an input-output matrix describing the monetary flows of an economy:

$$
\boldsymbol{Z}+\boldsymbol{f}=\boldsymbol{x}
$$

where $\boldsymbol{Z}$ is a matrix representing intermediate consumption, $\boldsymbol{f}$ is the vector of final demand, and $\boldsymbol{x}$ is the vector of gross output. Define $\boldsymbol{A}$ as the technical coefficient matrixes, such that

$$
A=Z(\widehat{x})^{-1}
$$

where each element of $\boldsymbol{A}$ is defined as $a_{i j}=z_{i j} / x_{j}$, which corresponds to the proportion of input that industry $j$ needs from industry $i$ to produce $\$ 1$ of product. $\widehat{x}$ is the diagonal matrix with the elements of vector $\boldsymbol{x}$.

Using (2) and solving Equation (1) for $\boldsymbol{x}$, we have:

$$
A x+f=x
$$

after algebraic manipulations, we obtain:

$$
\boldsymbol{x}=\boldsymbol{L} \boldsymbol{f}
$$


where $\boldsymbol{L}$ is the Leontief inverse matrix, defined as $\boldsymbol{L}=(\boldsymbol{I}-\boldsymbol{A})^{\mathbf{- 1}}=\left[l_{i j}\right]$, and its elements can be understood to be the direct and indirect requirements of industry $j$ for meeting a unit of output growth in industry $i$.

\subsection{Disaggregation Procedure}

To assess the interdependence of the Brazilian cultural industries, we use estimated inputoutput tables (Guilhoto and Sesso Filho, 2005, 2010) ${ }^{8}$ for 56 industries (Appendix 1) and 110 commodities for 2005 and 2009, using 2000 prices. From these 56 industries, however, the IBGE considers only two as cultural activities: Public and Private Education. Nonetheless, the cultural activities have a much larger participation in the production structure than education industries alone. To disaggregate such activities, we used information from the Annual Service Survey, the Annual Industry Survey, and the System of Information and Cultural Indices from IBGE. These surveys ${ }^{9}$ provide information to disaggregate some of the industries, enabling us to identify 13 cultural sectors.

Ideally, the surveys would provide us with three sets of information that we could use to modify our input-output (I-O) tables: the purchases and sales between industries, the payments to labor and capital, and the consumption by families, government, investment, and the trade balance. However, they provide only pieces of this information, namely, total output by industry, total intermediate consumption (demand side), and total value added. Below we describe how we use that information to disaggregate the cultural industries in the I-O tables.

First, we identify and match these industries to their corresponding I-O industries. Appendices 2 and 3 present each cultural activity from the Annual Industry Survey used and their respective I-O industry for 2005 and 2009. Appendix 4 presents the activities from the Annual Service Survey used and their respective I-O industry. From the information provided, we use the output information and the intermediate consumption, given that the total value added is the difference between the former and the latter. The gross output is used to disaggregate the cultural industries, and the intermediate consumption is used to provide better estimates of the transaction table.

To calculate the share of cultural and non-cultural portions in each identified industry, we use both the surveys and the I-O table. From the surveys, we get the share of total output for each identified cultural industry with respect to the total amount for that survey (industry or service). Then, we reconcile this share with the I-O table by dividing it by the share of total output in the survey with respect to the total output in the I-O table industries representative of that survey. Formally, we have:

$$
\begin{gathered}
\mathrm{r}_{i}^{C}=\left(g_{i}^{S} / \sum g_{i}^{S}\right) *\left(\sum g_{i}^{S} / \sum g_{i \in S}^{I O}\right) \\
\mathrm{r}_{i}^{N C}=\left(\sum g_{i}^{I O} / \sum g_{i \in S}^{I O}\right)-\mathrm{r}_{\mathrm{i}}^{C} \\
\mathrm{p}_{i}^{C}=\mathrm{r}_{i}^{C} /\left(r_{i}^{C}+r_{i}^{N C}\right) \\
\mathrm{p}_{i}^{N C}=1-\mathrm{p}_{i}^{C}
\end{gathered}
$$

where $i$ are industries, $g$ is gross output, superscript $S$ is the survey and $I O$ is the I-O table.

\footnotetext{
${ }^{8}$ Available at http://www.usp.br/nereus/

${ }^{9}$ For the Trade industry, we considered the share of cultural goods that is available at System of Information and Cultural Indices, which they refer to as Cultural Trade.
}

(c) Southern Regional Science Association 2018. 
Table 4: Cultural Industries in the Input-Output Tables

\begin{tabular}{ll}
\hline Code & Cultural industries \\
\hline 13C & Printing and Publishing \\
22C & Manufacture of tapes and disks \\
31C & Manufacture of computers and accessories \\
33C & Manufacture of telecommunication equipment \\
34C & Manufacture of optical, photographical and movie equipment \\
39C & Jewelry, music instruments and toys \\
42C & Cultural Trade \\
44C & Telecommunication, edition and news agencies \\
47C & Maintenance of computers and communication equipment \\
49C & Travel agencies and related services \\
50C & Private Education \\
52C & Recreational and cultural activities and education \\
54C & Public Education \\
\hline \hline
\end{tabular}

We use the calculated share to disaggregate the cultural portion out of the identified industries. By doing so, we ensure that the total intermediate consumption on the sale side had the calculated share. Hence, we assume initially both cultural and non-cultural portions have the same sales structure. With the intermediate consumption on the purchase side, we can have better estimates for the cultural industries. These will be used later in the so-called RAS procedure, which is a bi-proportional matrix balance technique.

Using the disaggregated transactions table, we calculate the technical coefficients matrix more details in the section below - and a Local Quotient (LQ) matrix. We use the LQ matrix to improve the technical requirement matrix. With the improved technical coefficient matrix, we obtain an initial transaction table that is rebalanced and improved using the RAS method. We performed some sensitivity analysis by comparing the original table and the disaggregated one, focusing on the sectors that were not disaggregated as they should have similar results. Thus, the initial 56-industry I-O table becomes a 67 -industry I-O table. ${ }^{10}$ Table 4 presents the disaggregated cultural industries.

Table 5 presents the share of cultural activities ${ }^{11}$ in their respective input-output industry. From the 13 industries that contain some sort of cultural activities, the ratio for cultural to noncultural activities is generally similar between 2005 and 2009. However, for one industry - Journal, magazines and disks (13) - this ratio changes from around 25.3 percent cultural in 2005 to 5.4 percent cultural in 2009. We believe that these changes are due to a change in the industry classification system ${ }^{12}$ used in Brazil.

\section{EXPLORATORY ANALYSIS OF THE CULTURAL INDUSTRIES}

\footnotetext{
${ }^{10}$ The disaggregated I-O table is available as supplemental material to this paper.

11 The cultural industry in sector 22 is the "Manufacturing of blank media". In 2005 there was only one firm with no production (less than 10 employees), while in 2009 there were four firms with some production.

12 CNAE (Classificação Nacional de Atividades Econômicas) is the Brazilian code system for economic activities and follows the International Standard Industry Classification. In 2005, we have information following the code system CNAE 1.0 and in 2009 CNAE 2.0. Both classifications are compatible, and while issues may arise due to this change in the classification system, they will not bias our results.
} 
Table 5 - Share of Cultural Activities in each Disaggregated Input-Output Industry

\begin{tabular}{ll|cccc}
\hline \hline & \multicolumn{3}{|c}{2005} & \multicolumn{2}{c}{2009} \\
& Industry & Cultural & Non-Cultural & Cultural & Non-Cultural \\
\hline 13 & Journal, magazines and disks & $25.3 \%$ & $74.7 \%$ & $5.4 \%$ & $94.6 \%$ \\
22 & Other chemical products & $0.00 \%$ & $100.0 \%$ & $0.2 \%$ & $99.8 \%$ \\
31 & Office and computing supplies & $30.8 \%$ & $69.2 \%$ & $32.2 \%$ & $67.8 \%$ \\
33 & Electronic and communication & $39.0 \%$ & $61.0 \%$ & $41.4 \%$ & $58.6 \%$ \\
& equipment & & & \\
34 & Medical and optical equipment & $3.1 \%$ & $96.9 \%$ & $1.1 \%$ & $98.9 \%$ \\
39 & Other products & $3.2 \%$ & $96.8 \%$ & $1.7 \%$ & $98.3 \%$ \\
\hline 42 & Trade & $3.3 \%$ & $96.7 \%$ & $5.3 \%$ & $94.7 \%$ \\
\hline 44 & Information service & $21.4 \%$ & $78.6 \%$ & $25.1 \%$ & $74.9 \%$ \\
47 & Maintenance and repair & $2 . \%$ & $98.0 \%$ & $3.0 \%$ & $97.0 \%$ \\
49 & Enterprise service & $0.6 \%$ & $99.4 \%$ & $0.6 \%$ & $99.4 \%$ \\
50 & Private Education & $100.0 \%$ & $0.0 \%$ & $100.0 \%$ & $0.0 \%$ \\
52 & Community and person services & $0.9 \%$ & $99.1 \%$ & $1.1 \%$ & $98.9 \%$ \\
54 & Public Education & $100.0 \%$ & $0.0 \%$ & $100.0 \%$ & $0.0 \%$ \\
\hline \hline
\end{tabular}

We are studying a developing sector in the country, but because there are few studies dealing with all the possible impacts of the cultural sector on the economy that consider both direct and indirect effects, we use several methodologies to conduct our analysis. As we discuss below, the methodologies improve and complement one another and serve as a sensitivity analysis for our conclusions. In this sense, we provide a broader view of the linkages between the cultural sector and the Brazilian production structure, which, in turn, help us paint a better picture of the interdependence of the cultural sector in Brazil.

Each section from 4.1 to 4.4 below presents one of the methodologies used to analyze the interdependence of the cultural industries in Brazil. Section 4.1 presents the multiplier analysis, Section 4.2 explains the linkage indices, Section 4.3 describes the fields of influence, and Section 4.4 presents the structural decomposition analysis.

\subsection{Multiplier Analysis}

For the multiplier analysis, we calculate three types of multipliers: output $\left(\mathrm{O}_{j}\right)$, value added $\left(\mathrm{V}_{j}\right)$, and employment $\left(\mathrm{E}_{j}\right)$. These measures provide a first outlook of the sectors in the economy. In other words, by looking at these different multipliers, we can determine the direct and indirect impact in the economy due to an exogenous shock.

First, let us define the employment coefficient as $e_{j}=N_{j} / x_{j}$ and the value added coefficient as $v_{j}=W_{j} / x_{j} . N_{j}$ is the number of employees in industry $j$, and $W_{j}$ is the total value added of industry $j$. Using these coefficients and the Leontief inverse, we can calculate the output multipliers and the type I value added and employment multipliers.

$$
\begin{gathered}
\mathrm{O}_{j}=\sum_{i=1}^{n} l_{i j} \\
\mathrm{E}_{j}^{I}=\sum_{i=1}^{n} e_{j} l_{i j} / e_{j} \\
\mathrm{~V}_{j}^{I}=\sum_{i=1}^{n} v_{j} l_{i j} / v_{j}
\end{gathered}
$$


Table 6: Average Output Multipliers for Aggregated Sectors, 2005 to 2009.

\begin{tabular}{lcccccc}
\hline \multirow{2}{*}{ Sector } & \multicolumn{2}{c}{ Output } & \multicolumn{2}{c}{ Value Added } & \multicolumn{2}{c}{ Employment } \\
\cline { 2 - 7 } & 2005 & 2009 & 2005 & 2009 & 2005 & 2009 \\
\hline Agriculture & 1.83 & 1.70 & 1.74 & 1.65 & 1.20 & 1.50 \\
Extractive & 1.93 & 1.88 & 1.97 & 2.04 & 11.18 & 14.39 \\
Manufacture & 2.18 & 2.02 & 2.61 & 2.39 & 12.61 & 15.29 \\
Trade & 1.50 & 1.50 & 1.36 & 1.35 & 3.80 & 4.15 \\
Service & 1.52 & 1.54 & 1.44 & 1.46 & 2.70 & 3.05 \\
Public Administration & 1.44 & 1.54 & 1.35 & 1.48 & 2.57 & 3.15 \\
Cultural & 1.70 & 1.87 & 1.76 & 2.00 & 1.58 & 1.66 \\
Average of economy & 1.93 & 1.88 & 2.16 & 2.10 & 8.09 & 9.84 \\
\hline \hline
\end{tabular}

In order to evaluate the importance of the cultural industries, we compare the aggregate results for these industries with respect to other central industries. In addition, we compare the relative importance of each cultural industry. In this sense, Table 6 presents the three multipliers for the years 2005 and 2009 for some aggregated sectors, while Figures 2 and 3 present the multipliers disaggregated for each cultural industry.

The six aggregated sectors we present are agriculture, extractive, manufacture, trade, services, and public administration. The extractive sector comprises all the mining, oil, and gas extraction industries. In Table 6, the only sector with a higher output multiplier than the average (1.93 and 1.88) is the manufacture sector (2.18 and 2.02). These results imply that every dollar spent on these sectors generates a total (direct and indirect) impact higher than the average sector in the Brazilian production structure. Although the cultural sector multiplier is not above the mean, it is higher than the multiplier for trade, services, and public administration. David and Guilhoto (2012) find similar results and point out that this is because of several problems in the production chain of cultural activities.

For the value added multiplier, only the manufacture sector has a larger multiplier than the average for the entire economy in both years. The cultural sector does not have high multipliers compared to the other sectors; its multiplier effect is larger than the one from the service and trade sectors, two sectors that are expected to have low value added multipliers. On the other hand, by looking at the employment multiplier, the cultural sector is still below the average; however, it has the third highest employment multiplier. This shows not only that the cultural sector is more labor intensive but also that it has linkages with sectors that demand more labor as well.

In Figures 2 and 3, we see that in terms of output multiplier, most cultural multipliers have decreased such that while most of them were above the average in 2005, this is not the case in 2009. As for the value added multiplier, they remain similar in both years such that half of the sectors are above the average multiplier. Lastly, we can see that the employment multipliers also decrease in general, especially for the service sectors. The employment multipliers for the industry sectors are the ones that increase during this period.

The results above provide an initial picture of the cultural industry in the Brazilian economy. Summing up, the cultural industries have high employment multipliers and low output and value added multipliers. This implies that a shock to the cultural sector would generate jobs but would not have much effect on GDP or production. Unfortunately, we cannot disaggregate the 
Figure 2 - Output, Value Added, and Employment Multipliers for Cultural Industries for 2005

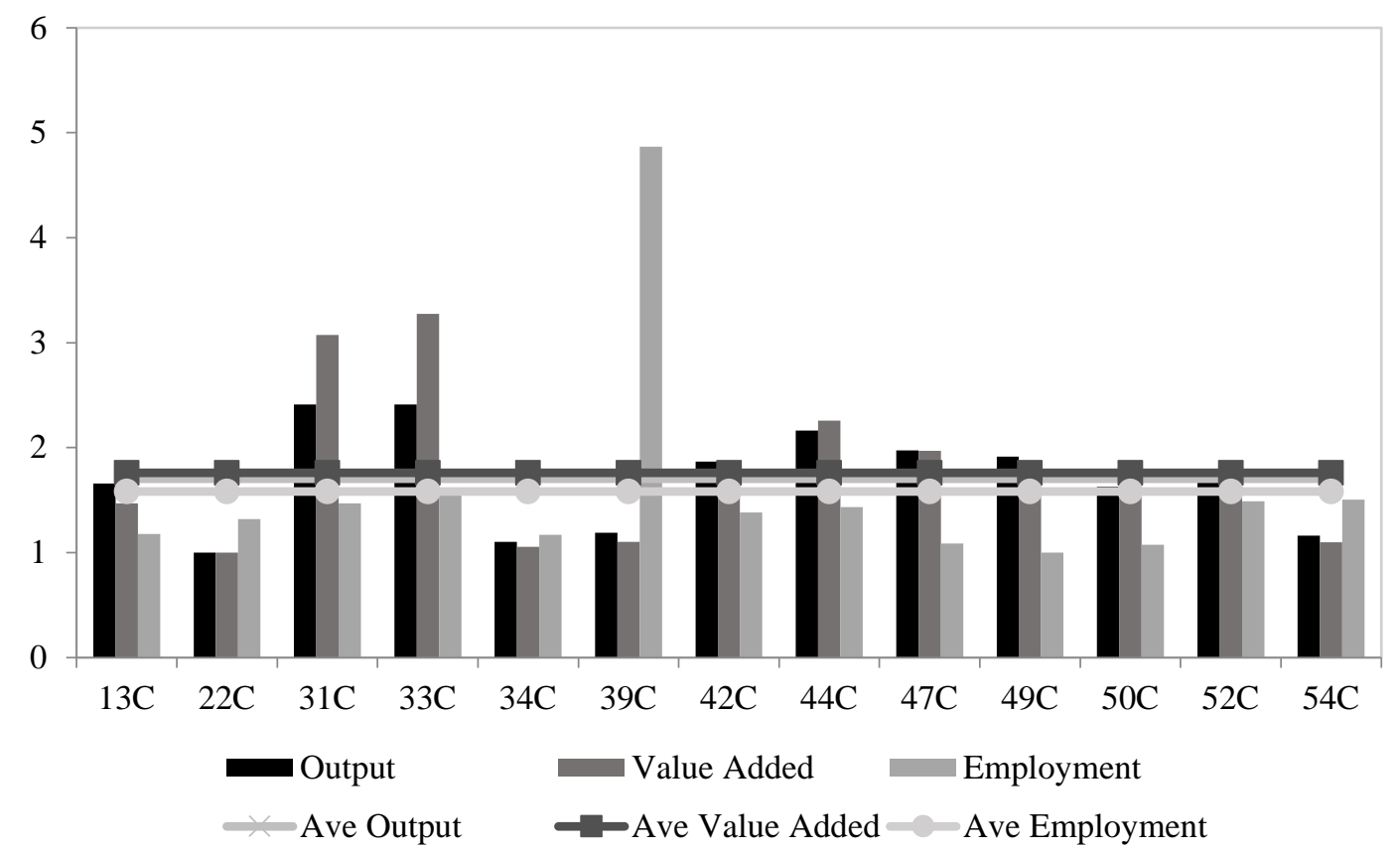

consumption of households to calculate the multiplier that would allow us to capture the incomeinduced effects.

Figure 3 - Output, Value Added, and Employment Multipliers for Cultural Industries for 2009

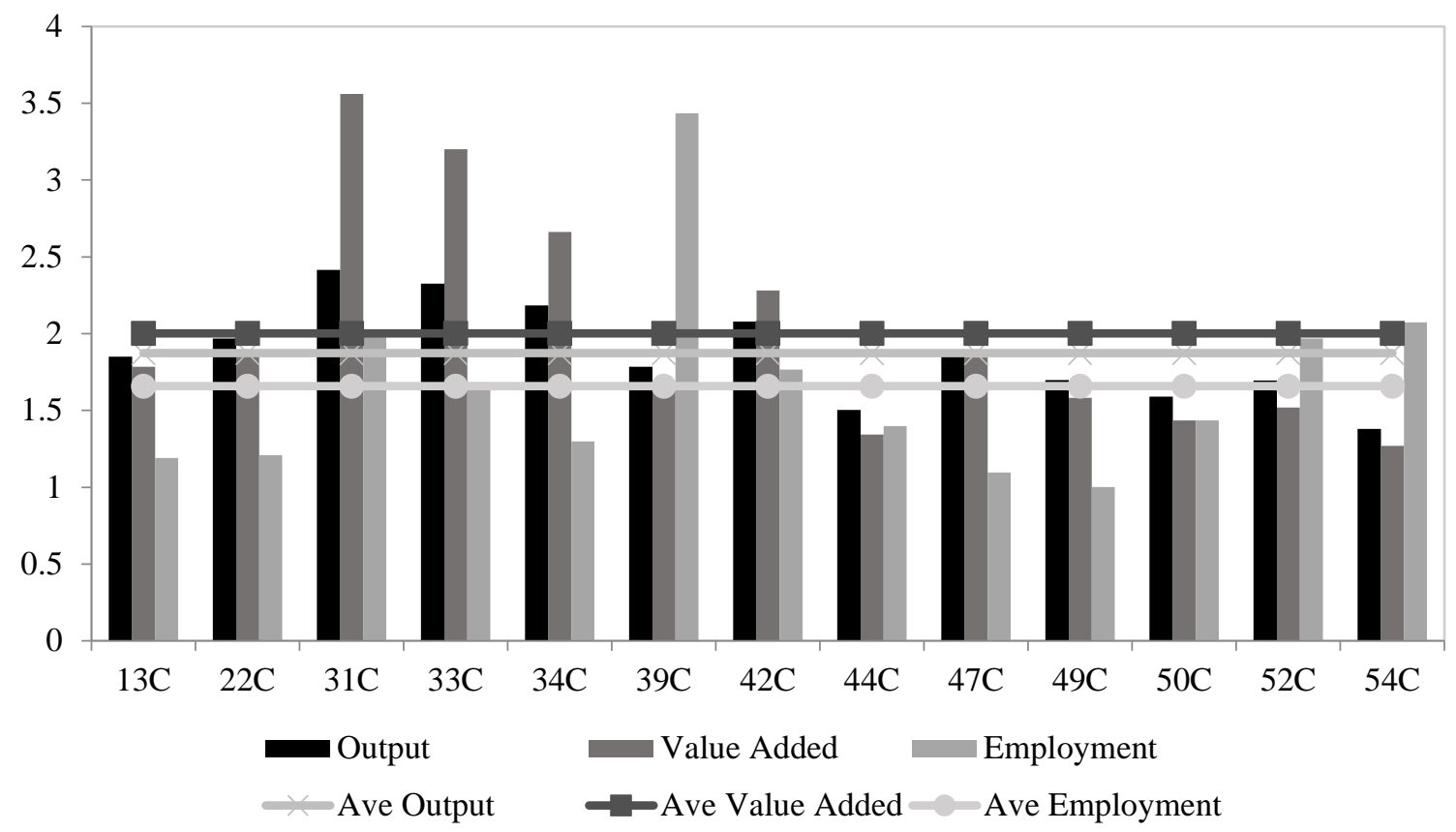

(c) Southern Regional Science Association 2018. 
We observe from the multipliers that the cultural sector is increasing in its importance throughout the period of analysis. For the three types of multipliers, there is an increase from 2005 to 2009. This result suggests that if this trend continues, the cultural sector can act as a key sector in terms of economic growth in the near future. For this leading role to take place, it is necessary for a continuum of movement towards the cultural activities.

\subsection{Linkage Indices}

We present three different linkage indices: the Hirschman-Rasmussen indices (HRI), the Pure Linkage Indices (PLI), and the extraction method. The HRI were introduced by Hirschman (1957) and Rasmussen (1958) and measure the importance of a sector in the economy. Guilhoto, Sonis, and Hewings (2005) devised a new methodology to calculate the linkage indices using the decomposition of the Leontief inverse matrix creating the PLI. The authors created this index by combining ideas from work by Cella (1984), Clements (1990), and Miyazawa (1976). There is a key difference between the two indices; HRI does not include the size of the sector in the economy to determine whether or not the sector is a key one while the PLI does.

The extraction method used in this paper is based on the work of Dietzenbacher et al. (1993). The authors develop their measure based on the work of Strassert (1968-1969). This method evaluates the impact of a hypothetical isolation of one industry (or region) on the rest of the economy. This linkage index not only allows us to observe the importance of a sector due to its interdependence and size, but it also allows us to map which sectors are most affected by a shock in the extracted sector.

The HRI is one of the most traditional measures to determine if a sector, or group of sectors, is important in the production structure of a country. The backward linkage (BL), $U_{j}$, provides the dependence of sector $j$ from all the other sectors of the economy, while the forward linkage (FL), $U_{i}$, provides the dependence of all the other sectors of the economy from sector $j$. Values that are higher than one for the index is evidence that a sector is above the national mean. Mathematically,

$$
\begin{aligned}
U_{j} & =\frac{\sum_{i=1}^{n} l_{i j}}{\sum_{i=1}^{n} \sum_{j=1}^{n} l_{i j}} \\
U_{i} & =\frac{\sum_{j=1}^{n} g_{i j}}{\sum_{i=1}^{n} \sum_{j=1}^{n} g_{i j}}
\end{aligned}
$$

where $\left[g_{i j}\right]=\boldsymbol{G}=(\boldsymbol{I}-\boldsymbol{K})^{-\mathbf{1}}$ is the element of the Ghosh $(\boldsymbol{G})$ matrix, such that $\boldsymbol{K}=\left[k_{i j}\right]$ is the technical coefficient matrix defined by $k_{i j}=z_{i j} / x_{i}$.

Figure 4 shows the results for the HRI. Sectors with values above unit are considered more important to the production structure. If both BL and FL are above unit, it is considered a key sector. Three cultural industries are considered a key sector in 2005: cultural trade (42C), telecommunication, edition, and news agencies (44C), and travel agencies and related services (49C). For 2009, the cultural industries considered key-sectors are printing and publishing (13C) and maintenance of computers and communication equipment (47C). Another sector that appears to be relevant is the sector electronic and communication equipment (33C), with above unit backward linkage and a high forward linkage in both years.

The Pure Linkage Index (PLI), similar to the HRI, has a backward and forward measure. The Pure Backward Linkage (PBL) yields the pure impact of the economy on the value of the total production in sector $j$, i.e., the impact that is both free from demand for inputs from sector $j$ and 
Figure 4 - Backward and Forward Indices for the Cultural Industries, 2005 and 2009
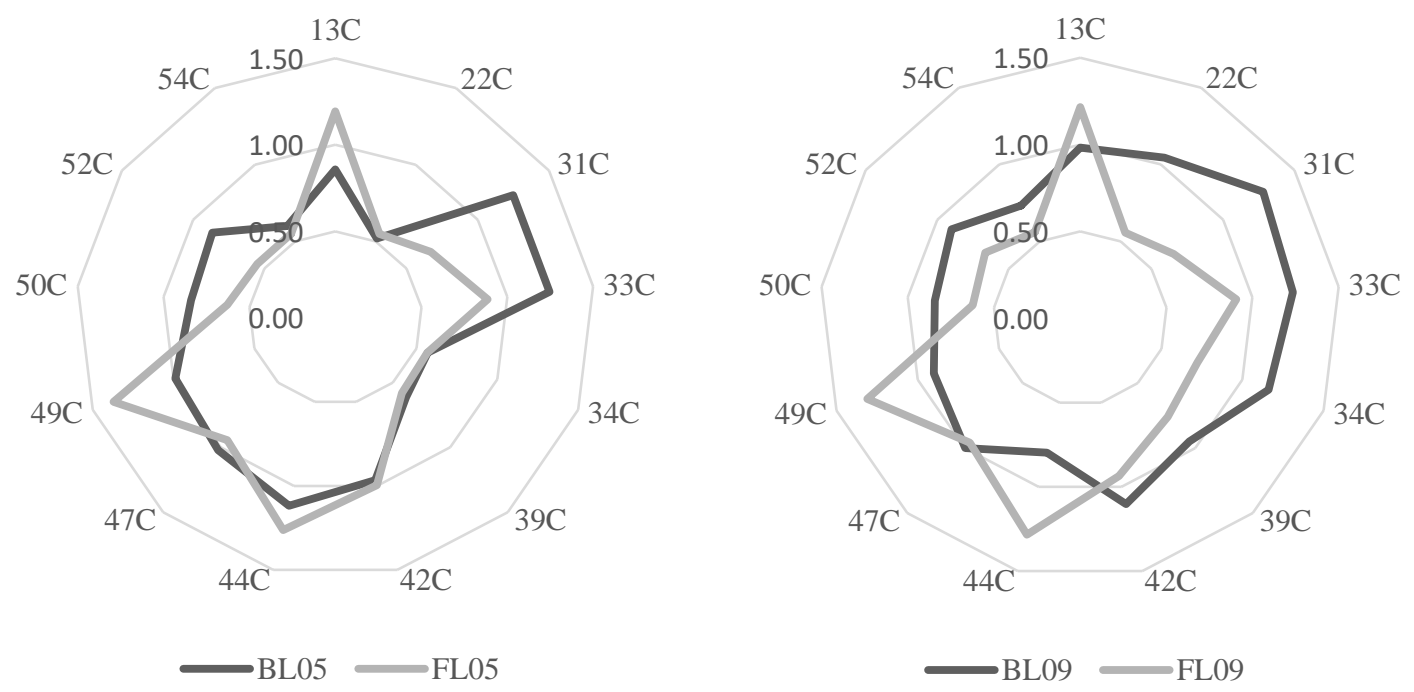

feedback from the economy to sector $j$, and vice-versa. The Pure Forward Linkage (PFL) yields the pure impact on sector $j$ of the total production in the rest of the economy. Another advantage of the PLI is the possibility of obtaining the total index (Pure Total Linkage - PTL) through the sum of PBL and PFL. To make it easier to compare PLI and HRI, we standardize the PLI, dividing the pure index of each sector by the mean of pure index in the economy.

Mathematically, ${ }^{13}$ the Pure Linkage indices are:

where $\Delta_{j}=\left(\boldsymbol{I}-\boldsymbol{A}_{\boldsymbol{j} \boldsymbol{j}}\right)^{-1}$ and $\Delta_{\boldsymbol{r}}=\left(I-\boldsymbol{A}_{\boldsymbol{r} r}\right)^{-1}$, and $\mathbf{Y}$ is the final demand.

Figure 5 presents the results for the PLI. Different from the HRI, if the Pure Total Linkage Normalized (PTLN) is above unit, we define it as a key sector. For the cultural industries, there is no key sector in either of the years analyzed. The difference in the results is due to the size of this industry in the production structure that now is considered. The private education (50C) and public education (54C) industries are quite important as well, especially with respect to backward effects, i.e., they demand more from the economy to meet a final demand shock than other cultural sectors.

The extraction method is another measurement of the linkages in the economy. This linkage measure, inspired by the work of Cella (1984) and Clements (1990), complements the previous two indices by mapping the sectors that are impacted by an exogenous shock in the hypothetical extracted sector. Mathematically, the impact vectors are

$$
x^{1}-\bar{x}^{1}=\left(I-A^{11}\right)^{-1} A^{1 R} L^{R R}\left[f^{R}+A^{R 1}\left(I-A^{11}\right)^{-1} f^{1}\right]
$$

and

\footnotetext{
${ }^{13}$ Rewriting the matrix of Technical Coefficients as, $\boldsymbol{A}=\left[\begin{array}{cc}\boldsymbol{A}_{j j} & \boldsymbol{A}_{j r} \\ \boldsymbol{A}_{r j} & \boldsymbol{A}_{r r}\end{array}\right]=\left[\begin{array}{cc}\boldsymbol{A}_{j j} & \boldsymbol{A}_{j r} \\ \boldsymbol{A}_{r j} & \mathbf{0}\end{array}\right]+\left[\begin{array}{cc}\mathbf{0} & \mathbf{0} \\ \mathbf{0} & \boldsymbol{A}_{r r}\end{array}\right]$, we can calculate $\boldsymbol{L}=$ $(\boldsymbol{I}-\boldsymbol{A})^{-\mathbf{1}}=\left(\begin{array}{cc}\boldsymbol{B}_{j j} & \boldsymbol{B}_{j r} \\ \boldsymbol{B}_{r j} & \boldsymbol{B}_{r r}\end{array}\right)=\left(\begin{array}{cc}\Delta_{j j} & \mathbf{0} \\ \mathbf{0} & \Delta_{r r}\end{array}\right)\left(\begin{array}{cc}\Delta_{j} & \mathbf{0} \\ \mathbf{0} & \Delta_{r}\end{array}\right)\left(\begin{array}{cc}\boldsymbol{I} & \boldsymbol{A}_{j r} \Delta_{r} \\ \boldsymbol{A}_{r j} \Delta_{j} & \boldsymbol{I}\end{array}\right)$.
}

(C) Southern Regional Science Association 2018. 
Figure 5 - Pure Linkage Indices for Cultural Industries, 2005 and 2009.

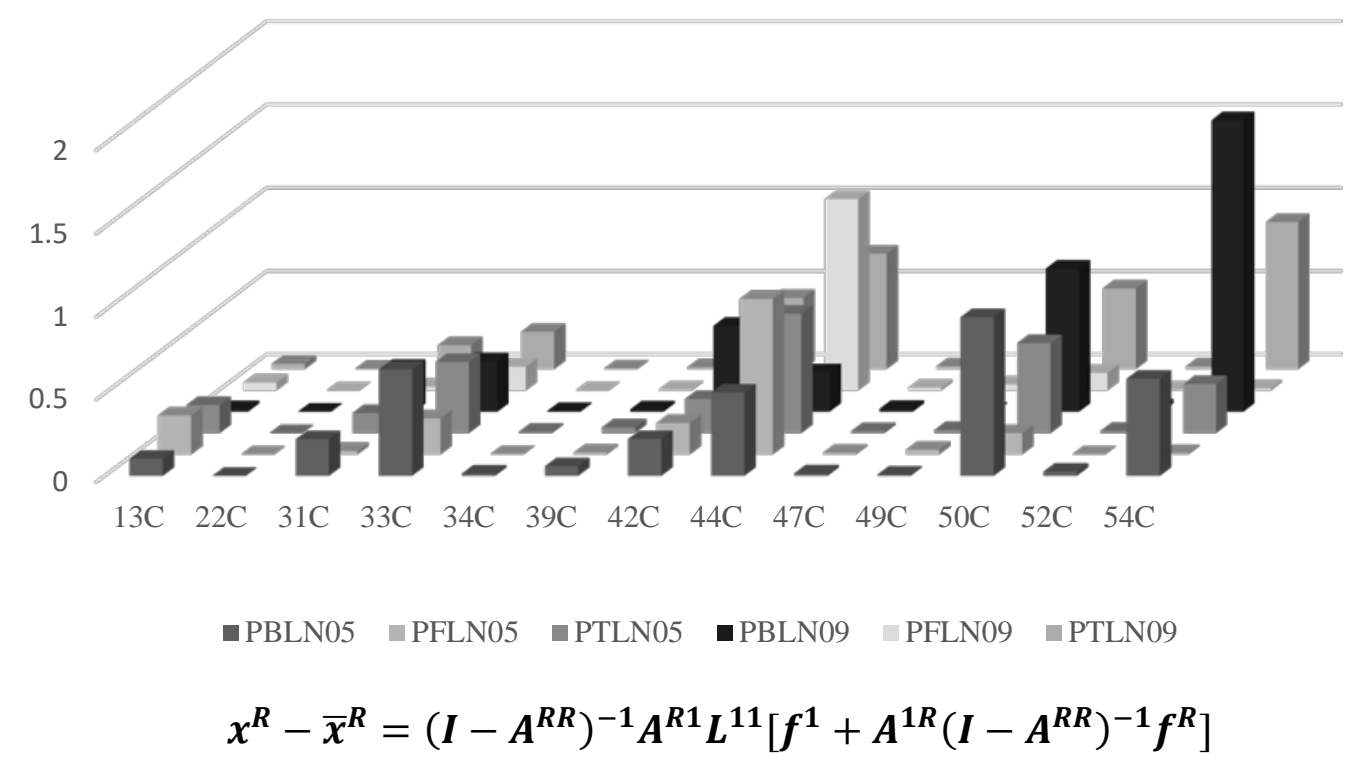

where $\boldsymbol{A}$ is the matrix of technical coefficient, $\boldsymbol{L}$ is the Leontief inverse, $\boldsymbol{f}$ is the final demand, superscript 1 represents one sector (or region), superscript $R$ represents the rest of the economy (sectors or regions), and $\overline{\boldsymbol{x}}$ is output of the rest of the economy with the extraction of the sector (or region).

According to Dietzenbacher et al. (1993), both Equations (16) and (17) are backward measures. On the one hand, Equation (16) captures the dependence of a hypothetical extracted cultural industry on the rest of the economy. On the other hand, Equation (17) captures the dependence of the rest of the economy on a hypothetical extracted cultural industry. We present the results for the extraction method for the years 2005 and 2009 in Tables 7 and 8, respectively. We note that the results are presented as aggregated effects, i.e., we sum the elements of the differences to get the total impact (loss) of hypothetically extracting one cultural industry of the production structure.

Comparing the results from both tables, it is clear that the cultural industries became more important in 2009 than they were in 2005. This can be verified in two ways. First, we notice a higher impact of the hypothetical extraction on each industry itself. This shows that the extracted sector is more interconnected with the other industries in the economy because there is an increased dependency on them. Moreover, we see that other cultural industries are becoming more dependent on the extracted industry, showing an increased importance of such industries to the cultural production structure. We should note, however, that the linkage results provide a latent potential of impact on the economy. In other words, these are not observed impacts yet but rather possible impacts that may differ depending on the true interdependency between the cultural sectors.

This set of results shows how the cultural activities affect the productive chain by making intra- and inter-sectorial analysis. The hypothetical extraction results (Tables 7 and 8) show that during the period of analysis, there is a slight increase in the spread of interconnection between the cultural sector and the other sectors in the economy. This implies that the cultural sector is also 
Table 7: Extraction Method for Year 2005 (in \%)

\begin{tabular}{lccccccccccccc}
\hline \hline & $13 \mathrm{C}$ & $22 \mathrm{C}$ & $31 \mathrm{C}$ & $33 \mathrm{C}$ & $34 \mathrm{C}$ & $39 \mathrm{C}$ & $42 \mathrm{C}$ & $44 \mathrm{C}$ & $47 \mathrm{C}$ & $49 \mathrm{C}$ & $50 \mathrm{C}$ & $52 \mathrm{C}$ & $54 \mathrm{C}$ \\
\hline Primary & 10 & - & 16 & 14 & 28 & 18 & 13 & 10 & 18 & 10 & 6 & 11 & 6 \\
Secondary & 32 & - & 58 & 46 & 36 & 49 & 41 & 40 & 38 & 34 & 22 & 56 & 68 \\
Tertiary & 9 & - & 18 & 21 & 18 & 16 & 12 & 13 & 15 & 9 & 48 & 31 & 24 \\
Cultural & 1 & - & 1 & 1 & 1 & 1 & 1 & 0 & 1 & 1 & 2 & 1 & 2 \\
$\begin{array}{l}\text { Removed } \\
\text { Sector }\end{array}$ & 48 & - & 8 & 19 & 17 & 15 & 33 & 37 & 28 & 46 & 22 & 0 & 1 \\
\hline \hline
\end{tabular}

Note: The percentage was calculated by summing the impacts in all sectors $\left(x^{R}-\bar{x}^{R}\right)$ and the impact in the removed sector itself $\left(x^{1}-\bar{x}^{1}\right)$ and then calculating share of the sum of sector with respect to this total. Removed sector is the sector in the column, which was hypothetically extracted.

important in terms of leakages, which means that an improvement or decrease in its economic activity will affect the economy through the productive chain. Thus, this highlights the importance of the sector for both public and private agents in terms of the contribution of cultural activities to the economy.

An example of the relative importance of the Cultural sector for the whole economy is the UK. In the beginning of the 1990s, they regarded the cultural sector as a strategic sector for the economy, implementing several policies to support the sector. These policies strengthened all the productive chains, leading to an increase in the share of the Cultural sector in GDP, employment and income (Wagner, 2016).

Taking the three measures presented, it is noticeable that the cultural industries in Brazil are gaining importance in the economy from 2005 to 2009. The main channel for this increase in importance seems to be the interdependence with other sectors in the economy, especially the secondary sectors. However, the cultural industries are still smaller compared to other industries in terms of their relative importance. The next section presents the fields of influence, which measure the spillovers of shock throughout the production structure.

Table 8 - Extraction Method for Year 2009 (in \%)

\begin{tabular}{|c|c|c|c|c|c|c|c|c|c|c|c|c|c|}
\hline & $13 \mathrm{C}$ & $22 \mathrm{C}$ & $31 \mathrm{C}$ & $33 \mathrm{C}$ & $34 \mathrm{C}$ & $39 \mathrm{C}$ & $42 \mathrm{C}$ & $44 \mathrm{C}$ & $47 \mathrm{C}$ & $49 \mathrm{C}$ & $50 \mathrm{C}$ & $52 \mathrm{C}$ & $54 \mathrm{C}$ \\
\hline Primary & 19 & 7 & 21 & 20 & 43 & 29 & 14 & 10 & 20 & 12 & 5 & 17 & 7 \\
\hline Secondar & & & & & & & & & & & & & \\
\hline $\mathrm{y}$ & 22 & 58 & 50 & 36 & 23 & 30 & 39 & 23 & 31 & 23 & 53 & 48 & 59 \\
\hline Tertiary & 12 & 16 & 21 & 21 & 19 & 17 & 18 & 9 & 15 & 10 & 35 & 20 & 29 \\
\hline Cultural & 1 & 19 & 1 & 1 & 2 & 2 & 1 & 0 & 1 & 1 & 3 & 2 & 3 \\
\hline Removed & & & & & & & & & & & & & \\
\hline Sector & 46 & 0 & 7 & 22 & 13 & 22 & 28 & 59 & 33 & 54 & 5 & 14 & 1 \\
\hline
\end{tabular}




\subsection{Fields of Influence}

The fields of influence analysis is complementary to the linkage indices as it describes the distribution in changes in the technical direct coefficients in the economic system, enabling us to determine which are the most important relations in the production structure (Sonis and Hewings, 1992; Guilhoto, 2009). Define $\boldsymbol{E}=\left[\varepsilon_{i j}\right]$ as the matrix with incremental variation to the matrix of technical coefficients $\boldsymbol{A}$, such that $\varepsilon_{i j}=\varepsilon$ if $i=i_{1}$ and $j=j_{1}$ and 0 ; otherwise, $i_{1}$ and $j_{1}$ map the coefficient being shocked. Also, define $\boldsymbol{L}\left(\varepsilon_{i j}\right)=(\boldsymbol{I}-\boldsymbol{A}-\boldsymbol{E})^{-1}$. The approximation of the fields of influence from a small change ${ }^{14}(\varepsilon)$ in $a_{i j}$ is $\boldsymbol{F}\left(\varepsilon_{i j}\right)$, such that

$$
\boldsymbol{F}\left(\varepsilon_{i j}\right)=\frac{\left[L\left(\varepsilon_{i j}\right)-L\right]}{\varepsilon_{i j}}
$$

where $\boldsymbol{F}\left(\varepsilon_{i j}\right)$ is a matrix, with dimensions $N \mathrm{x} N$, of the field of influence of coefficient $a_{i j}$. $N$ is the number of industries in the input-output table. To evaluate which coefficients have higher fields of influence, we must define $S_{i j}$ :

$$
S_{i j}=\sum_{t=1}^{n} \sum_{p=1}^{n}\left[f_{t p}\left(\varepsilon_{i j}\right)\right]
$$

where $S_{i j}$ is the associated value to each $\boldsymbol{F}\left(\varepsilon_{i j}\right)$ matrix, i.e., the higher $S_{i j}$, the higher the field of influence of that relation in the economy.

Figures 6 to 9 present the results for the field of influence for the years 2005 and 2009. Figure 6 is the key for the other figures. We break the presentation of the results into three parts: the effect within the cultural sectors (Figure 7); the effect of the cultural sector as suppliers (Figure 8); and the effect of the cultural industries as consumers (Figure 9). The darker the link between the sectors, the more important this "chain" is to the production structure. Looking side-by-side, it is possible to see how the importance of each "chain" evolved over the years.

Figure 7 shows the links between the trade sector (44C) and the sectors manufacture of tapes and disks (22C) and jewelry, music instruments and toys (39C) become above the average chain in the economy. Figure 8, shows an apparent evolution of the cultural sector as suppliers. Firstly, there are more important chains in 2009 than in 2005. Second, the links in 2009 are darker than those in 2005, which shows a gain in importance of the cultural sector. Finally, the main chains in 2005 were with the industries sectors while in 2009 it shifts to the service sectors.

Figure 9, in turn, shows the cultural sectors as consumers. In this case, although the trade sector (44C) becomes a more important buyer, other sectors lose their importance as suppliers to the cultural sector. It is noteworthy that the shift in importance from industry to service seems to be happening as well.

\subsection{Structural Decomposition Analysis}

Thus far, our analysis is static and only shows how the cultural industries were inserted into the Brazilian production structure in each year. The Structural Decomposition Analysis (SDA) provides an inter-temporal analysis. Therefore, by decomposing the changes in output from 2005

\footnotetext{
${ }^{14} \mathrm{~A}$ small change can be considered for example 0.001 . The $a_{i j}$ coefficients are the technical requirement, which is bounded between 0 and 1 .
} 
Figure 6 - Key for Figures 7 to 9

\begin{tabular}{|l|l|}
\hline & Below the Average \\
\hline & Between Average and 1 Standard Deviation \\
\hline & Between 1 and 2 Standard Deviations \\
\hline & Between 2 and 3 Standard Deviations \\
\hline & Above 3 Standard Deviations \\
\hline
\end{tabular}

Note: The average is for the whole economy

Figure 7 - Field of Influence within Cultural Sectors for 2005 and 2009

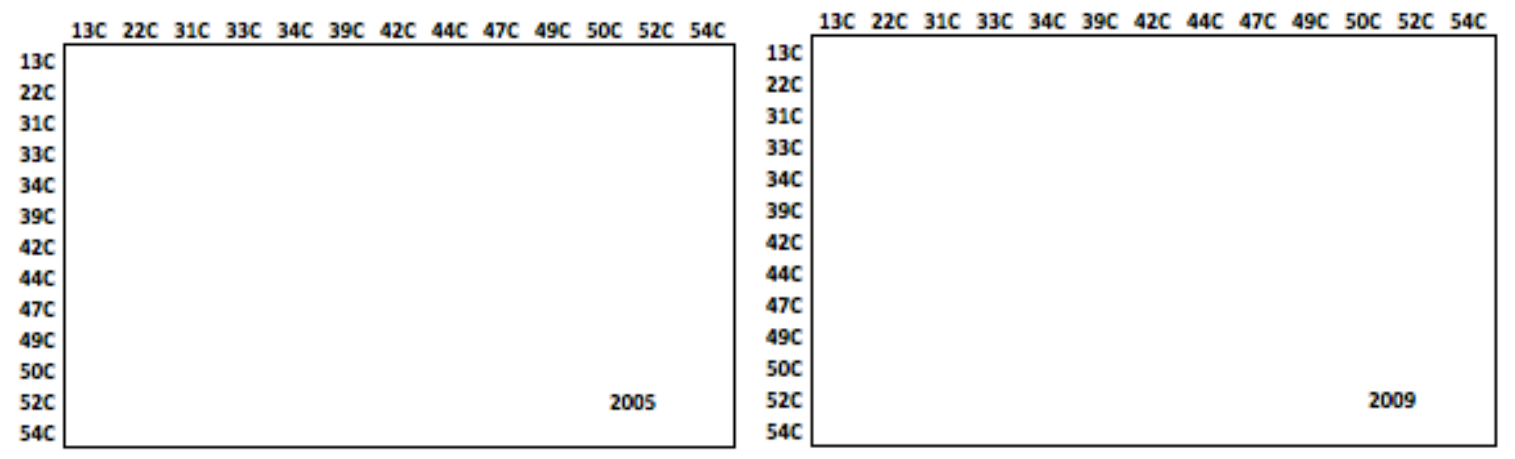

Note: The darker the shade of grey, the stronger the link between the sectors.

Figure 8 - Field of Influence: Cultural Sector as Supplier for 2005 and 2009
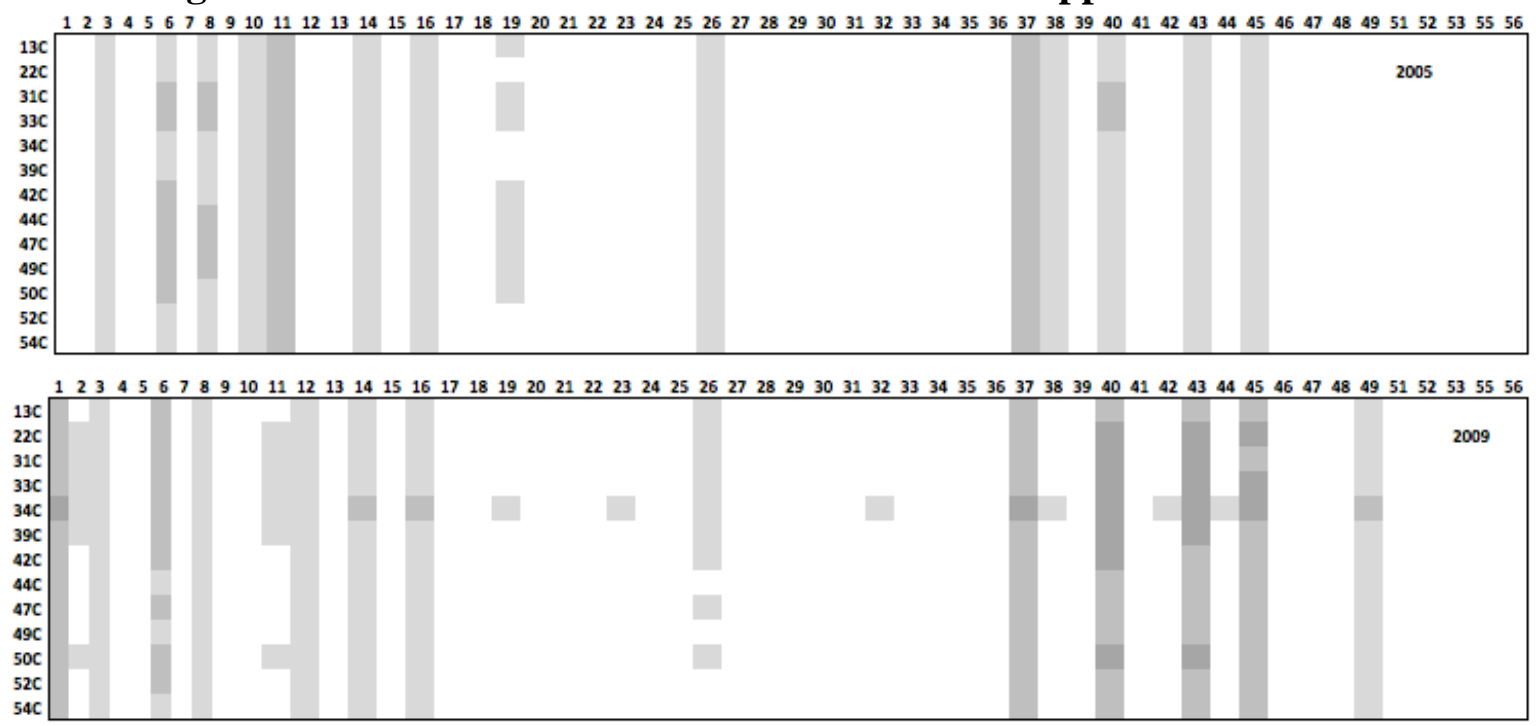

Note: The darker the shade of grey, the stronger the link between the sectors.

to 2009 we are able to inform not only how the cultural industries were important, but also why that was the case.

We perform a simple SDA analysis that decomposes the change in output in two sources, e.g., changes in technology (production structure) and changes in the final demand. Hence, we can visualize the driver in the change in output to determine whether it is an increase/decrease in the final demand or if it is a change in the way the goods are produced in the economy. Positive (negative) numbers in the technological (TEC) and final demand (FD) means there is an increase (decrease) in use of that sector by firms and family, respectively. Formally we can manipulate 
Figure 9 - Field of Influence: Cultural Sector as Consumer for 2005 and 2009

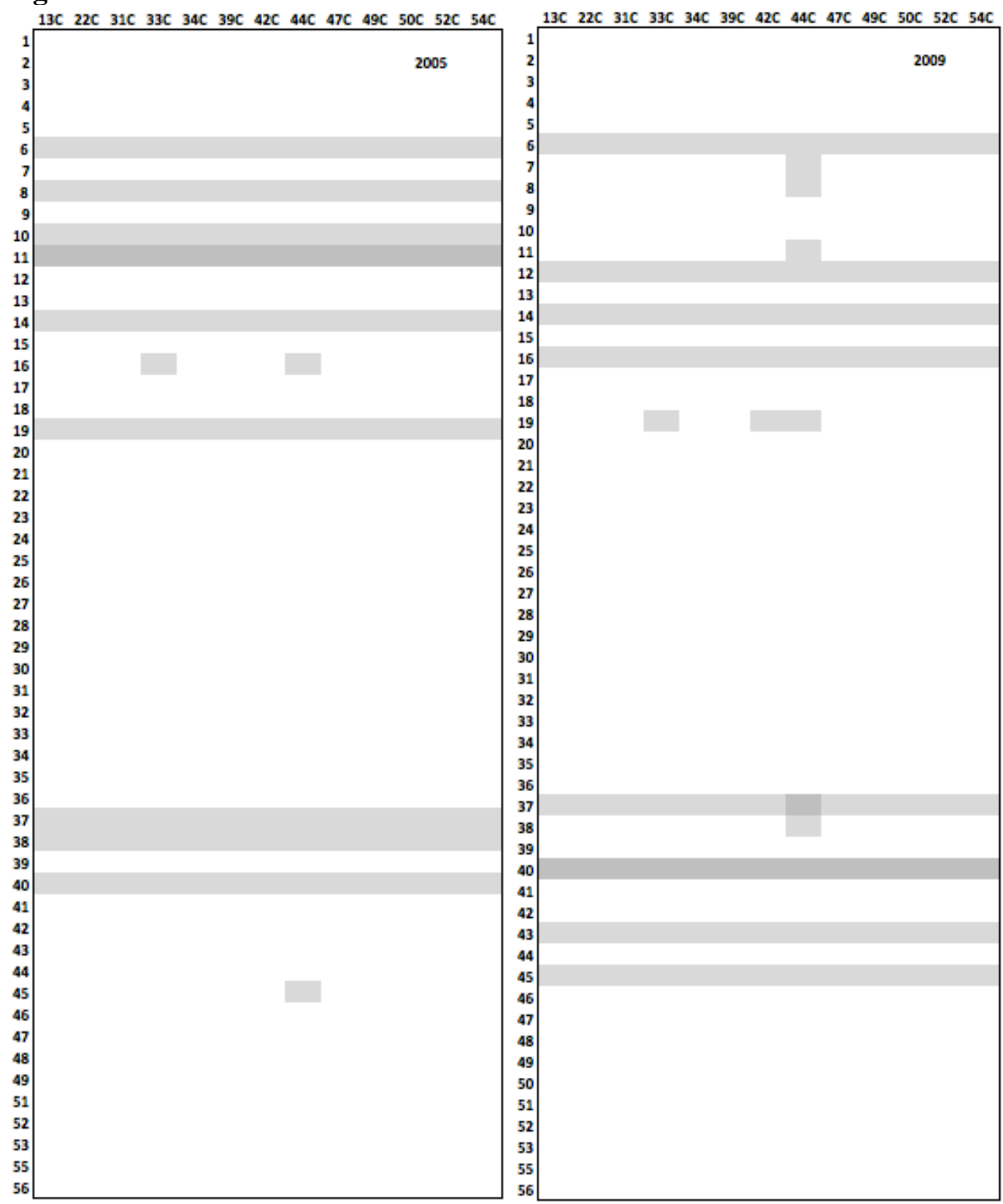

Note: The darker the shade of grey, the stronger the link between the sectors.

Equation (20) by using the relations $\Delta \mathbf{L}=\mathbf{L}^{\mathbf{1}}-\mathbf{L}^{\mathbf{0}}$ and $\Delta \mathbf{f}=\mathbf{f}^{\mathbf{1}}-\mathbf{f}^{\mathbf{0}}$ to obtain Equation (21).

$$
\begin{gathered}
\Delta x=\mathbf{x}^{\mathbf{1}}-\mathbf{x}^{\mathbf{0}}=\mathbf{L}^{1} \mathbf{f}^{\mathbf{1}}-\mathbf{L}^{\mathbf{0}} \mathbf{f}^{\mathbf{0}} \\
\Delta \mathbf{x}=\frac{\Delta L\left(\mathbf{f}^{\mathbf{1}}+\mathbf{f}^{\mathbf{0}}\right)}{2}+\frac{\left(\mathbf{L}^{1}+\mathbf{L}^{\mathbf{0}}\right) \Delta \mathbf{f}}{2}
\end{gathered}
$$

Table 9 presents the SDA analysis for aggregated sectors such as those in Table 6 . The results show that for the economy (Total), the final demand (FD) is the driver in the increase of output between 2009 and 2005. This is true for all the sectors as the FD component is larger than 
Table 9 - Structural Decomposition Analysis for Aggregated Sectors

\begin{tabular}{lccccc}
\hline \hline Sector & TEC $(\$)$ & FD $(\$)$ & $\begin{array}{c}\text { Output Diff. } \\
(\$)\end{array}$ & TEC (\%) & FD (\%) \\
\hline Agriculture & $-6,875$ & 88,845 & 81,970 & -8.4 & 108.4 \\
Extractive & $-14,009$ & 37,723 & 23,714 & -59.1 & 159.1 \\
Industries & $-90,559$ & 640,440 & 549,880 & -16.5 & 116.5 \\
Trade & 18,284 & 164,156 & 182,440 & 10.0 & 90.0 \\
Service & 82,248 & 481,843 & 564,091 & 14.6 & 85.4 \\
Public Administration & -160 & 185,136 & 184,976 & -0.1 & 100.1 \\
Cultural Sector & 3,007 & 103,979 & 106,986 & 2.8 & 97.2 \\
Total & $-8,063$ & $1,702,121$ & $1,694,058$ & -0.5 & 100.5 \\
\hline \hline
\end{tabular}

the technological component (TEC). For the cultural, trade, and services industries specifically, the increase in output is also explained by an increase of the use of cultural products in the intermediate consumption. This suggests that the cultural industries are gaining importance in the production structure, corroborating the findings in the Fields of Influence analysis.

Table 10 disaggregates the results for the specific cultural industries. In this table, the link between the cultural sector and changes in final demand becomes more explicit, as this is the main driver for changes in the output in the period analyzed. With the exception of the printing and publishing (13C) and manufacture of telecommunication equipment (33C) sectors, in all the other cultural sectors, final demand contributes more than 60 percent to the variation of the output between the years of analysis.

Taking into account that in Brazil the most important component of final demand is household consumption; with a share of more than 60 percent, the results imply that policies targeting the increase of household income would positively affect the Brazilian Cultural sector. It is interesting to note that for private education (50C) there is a negative technology share, meaning this is being less used in the production structure. Moreover, these results suggest that the cultural sector is more sensitive to business cycles than others; it grows rapidly in times of expansion and retracts more intensively in times of recession.

\section{CONCLUSIONS AND IMPLICATIONS}

This paper examines the importance of the cultural sector in the Brazilian economy by evaluating the interdependence of the cultural activities in the Brazilian production structure and its evolution from 2005 to 2009 using input-output analysis. This analysis fits well with the proposed question as the calculated indicators map several aspects of the sectorial interdependence, such as multipliers and linkages. The novelty of this approach is twofold: the disaggregated treatment of the cultural sector and the application for the Brazilian economy.

The output multipliers show that even though cultural activities are below the overall average, they are above important sectors, such as Trade, Services and Public Administration. The cultural sectors also have large employment multipliers - the third largest-indicating a potential incomeinduced effect. On the other hand, the value added multiplier is below the average of the economy and is smaller than most aggregated sectors.

The results of linkage indices indicate private and public education (sectors 50C and 54C) have important backward effects. Hence, even though there is no consensus in including education 
Table 10: Structural Decomposition Analysis Disaggregated for Cultural Sectors

\begin{tabular}{llccc}
\hline \hline & & Output Diff. & & \\
Code & Sector & $(\$)$ & TEC (\%) & FD (\%) \\
\hline 13C & Printing and Publishing & $-6,416$ & 78 & 22 \\
22C & Manufacture of tapes and disks & 30 & 0 & 100 \\
31C & Manufacture of computers and accessories & 2,829 & 1 & 99 \\
33C & Manufacture of telecommunication equipment & $-2,752$ & 73 & 27 \\
& Manufacture of optical, photographical and movie & & & \\
34C & equipment & $-2,640$ & 2 & 98 \\
39C & Jewelry, music instruments and toys & $-6,093$ & 2 & 98 \\
42C & Cultural Trade & 16,387 & 24 & 76 \\
44C & Telecommunication, edition and news agencies & 21,893 & 28 & 72 \\
& Maintenance of computers and communication & & & \\
47C & equipment & 673 & 29 & 71 \\
49C & Travel agencies and related services & 609 & 33 & 67 \\
50C & Private Education & 13,932 & -4 & 104 \\
52C & Recreational and cultural activities and education & 571 & 24 & 76 \\
54C & Public Education & 67,963 & 0 & 100 \\
\hline \hline
\end{tabular}

as a cultural activity, our results corroborate Markusen et al. (2008), providing more evidence that when evaluating the impact of cultural activities in a regional economy, it is important to consider sectors such as education. As for the spread effects (fields of influence), we verify only a slight interaction between cultural activities and non-cultural activities; however, this interaction shows a slight increase in 2009.

Finally, the Structural Decomposition Analysis shows us that the main driver to explain the increase in cultural output between 2005 and 2009 is the increase in final demand. However, different from most aggregated sectors, there is an increase in the use of cultural goods in the production structure. Hence, there is a gain in importance of the cultural sector in the Brazilian production structure.

A global picture of the changes in the cultural sector between 2005 and 2009 can be drawn. As expected, manufacturing sectors have higher backward linkages, but service sectors have higher forward linkages. The multipliers reinforce the interdependence of the manufacturing sectors. Also, there appears to be a transition in relative importance from manufacturing to services for the cultural sectors as is evidenced by the fields of influence, the extraction method, and the SDA. Thus, the results show that investments in cultural activities can produce positive results for the Brazilian economy in terms of income and employment effects. Therefore, our results are an important source of information to policymakers and private agents with respect to the cultural sector in the Brazilian economy.

One possible extension of this work would be to use an inter-regional input-output framework differentiating Brazil's regions or states, but due to the current lack of disaggregated data for the cultural industries, it is not possible to do so. However, by examining Tables 2 and 3 in light of the results in Section 4, it is possible to make some inferences. For instance, most industries in the country are concentrated in the Southeast; not only does it have the largest share of workers in the cultural sector, but it is also the region where the most is spent at a state level in 
cultural activities. This subsidy ${ }^{15}$ to cultural industries is important to explain this labor share, especially if we consider that most of the audio-visual sector (44C) is located in this region. The results show the importance of this sector, especially in terms of Forward Linkage and its relative high output multiplier.

Brazil has been experiencing recent changes in income and education. From 2001 to 2013, the average education level increased from 6.0 years to 7.7 years and the annual average per capita household income ${ }^{16}$ increased from $\mathrm{R} \$ 718.38$ in 2001 to $\mathrm{R} \$ 1047.95$ in 2013. It is expected that with higher income and education, the expenditure in cultural goods and services will increase. Therefore, understanding the Brazilian cultural production structure becomes key to learning potential growth opportunities or setbacks.

\section{REFERENCES}

Bertini, Alfredo. (2008) Economia da Cultura: a Indústria do Entretenimento e o Audiovisual no Brasil. São Paulo: Saraiva.

Blaug, Mark. (2001) "Where are we on Cultural Economics?,” Journal of Economic Surveys, 15, 123-143.

Bille, Trine, and Günter G. Schulze. (2006) “Culture in Urban and Regional Development,” in Ginsburgh, Victor and David Throsby (eds.) Handbook of the Economics of Art and Culture. Elsevier.

Bryan, Jane, Steve Hill, Max Munday, and Annette Roberts. (2000) “Assessing the Role of the Arts and Cultural Industries in a Local Economy,” Environment and Planning, 32, 13911408.

Cebr. (2015) “Contribution of the Arts and Culture Industry to the National Economy: An Update of our Analysis of the Macroeconomic Contribution of the Arts and Culture Industry to the National Economy,” Arts Council of England.

Cella, Guido. (1984) “The Input-Output Measurement of Interindustry Linkages,” Oxford Bulletin of Economics and Statistics, 4, 73-84.

Clements, Benedict J. (1990) "On the Decomposition and Normalization of Interindustry Linkages,” Economics Letters, 33, 337-340.

Collins, Alan and Jen Snowball. (2015) "Transformation, Job Creation and Subsidies to Creative Industries: The Case of South Africa’s Film and Television Sector,” International Journal of Cultural Policy, 21, 41-59.

Di Noto, Michael J. and Lawrence H. Merk. (1993) "Small Economy Estimates of the Impact of the Arts,” Journal of Cultural Economics, 17, 41-53.

David, Leticia and Joaquim J.M. Guilhoto. (2012) “O Potencial da Economia da Cultura no Brasil,” Unpublished paper presented at X Encontro Nacional da Associação Brasileira de Estudos Regionais e Urbanos, Recife, Brazil.

\footnotetext{
${ }^{15}$ For a more detailed discussion on subsidy to cultural industries see Frey (2011) and Collins and Snowball (2015)

${ }^{16}$ Data from Ipeadata (www.ipeadata.gov.br). Values are in R\$ (Brazilian Reais) from 2013

(C) Southern Regional Science Association 2018.
} 
Diniz, Sibele C. and Ana Flavia Machado. (2011) "Analysis of the Consumption of ArtisticCultural Goods and Services in Brazil,” Journal of Cultural Economics, 35, 1-18.

Dietzenbacher, E., Jan A. van der Linden, and Alben E. Steenge. (1993) “The Regional Extraction Method: EC Input-Output Comparisons,” Economic Systems Research, 5, 185-206.

Dolfman, Michael L., Richard J. Holden, and Solidelle F. Wasser. (2007) “The Economic Impact of the Creative Arts Industries: New York and Los Angeles,” Monthly Labor Review, 130, 21-34.

Earp, Fabio S. S. (2009) “O espectador eventual: notas sobre a demanda por cinema no Brasil,” Políticas Culturais em Revista, 2, 77-87.

Ferreira Neto, Amir B., Ricardo S. Freguglia, and Bernardo A. G. Fajardo. (2012) “Diferenciais salariais para o setor cultural e ocupações artísticas no Brasil,” Economia Aplicada, 16, 49-76.

Ferreira Neto, Amir B. and Fernando S. Perobelli. (2013) "Spatial Analysis of Cultural Activities in the Microregions of Minas Gerais,” EconomiA, 14, 139-157.

Frey, Bruno. (2011) "Public Support” in Towse, Ruth (ed), A Handbook of Cultural Economics. Edward-Elgar, 2nd Edition.

Gazel, Ricardo C. and Keith Schwer. (1997). "Beyond Rock and Roll: The Economic Impact of the Grateful Dead on a Local Economy,” Journal of Cultural Economics, 21, 41-55.

Golgher, André B. (2011) “A distribuição de indivíduos qualificados nas regiões metropolitanas brasileiras: A influência do entretenimento e da diversidade populacional,” Nova Economia, 21, 109-134.

Guilhoto, Joaquim J.M. and Umberto A. Sesso Filho. (2010) “Estimação da Matriz InsumoProduto Utilizando Dados Preliminares das Contas Nacionais: Aplicação e Análise de Indicadores Econômicos para o Brasil em 2005,” Economia \& Tecnologia, 23, 53-62.

Guilhoto, Joaquim J.M. and Umberto A. Sesso Filho. (2005) "Estimação da Matriz InsumoProduto a Partir de Dados Preliminares das Contas Nacionais,” Economia Aplicada, 9, 277-299.

Guilhoto, Joaquim J. M., Micahel Sonis, and Geoffrey J. D. Hewings. (2005) "Linkages and Multipliers in a Multiregional Framework: Integration of Alternative Approaches," Australasian Journal of Regional Studies, 11, 75-89.

Hirschman, Albert.O. (1958) The Strategy of Economic Development. Yale University Press: New Haven, Connecticut.

IBGE - Instituto Brasileiro de Geografia e Estatistica. (2013). "Sistema de Informações e Indicadores Culturais 2007-2010,” Available online at www.ibge.gov.br.

Llop, Maria and Josep M. Arauzo-Carod. (2012) "Identifying the Economic Impact Behind a Cultural Asset: An Input-Output Subsystems Analysis,” Annals of Regional Science, 49, 861-877.5

Machado, Ana Flavia, Alexandre Rabelo, and Artur Moreira. (2013) "Specificities of the Artistic Cultural Labor Market in Brazilian Metropolitan Regions between 2002 and 2010," Journal of Cultural Economics, 38, 237-251. 
Machado, Ana Flavia, Sibele C. Diniz, and Rodrigo Simões. (2013) "Urban Amenities and the Development of Creative Clusters: The Case of Brazil,” Current Urban Studies, 1, 92-101.

Machado, Ana. Flavia., Sibele C. Diniz, and Tatiane A. Menezes. (2010) "Perfil dos consumidores de cinema no Brasil metropolitano,” Unpublished paper presented at VIII Encontro da Associação Brasileira de Estudos Regionais e Urbanos, Juiz de Fora, Brazil.

Markusen, Ann. (2007) “A Consumption Base Theory of Development: An Application to the Rural Cultural Economy,” Agricultural and Resource Economics Review, 36, 9-23.

Markusen, Ann., Gregory Wassall, Douglas DeNatale, and Randy Cohen. (2008) "Defining the Creative Economy: Industry and Occupational Approaches,” Economic Development Quarterly, 22, 24-45.

Mellander, Charlotta. (2009) "Creative and Knowledge Industries: An Occupational Distribution Approach,” Economic Development Quarterly, 23, 294-305.

Miller, Ronald E. and Peter D. Blair. (2009) Input-output Analysis: Foundations and Extensions. Cambridge University Press: Cambridge, Massachusetts.

Miyazawa, Kenichi. (1976) Input-Output Analysis and the Structure of Income Distribution. Springer.

National Endowment for the Arts (1986), “The arts in the GNP”, Journal of Cultural Economics, Vol. 10, No. 1 ,pp. 77-82.

National Endowment for the Arts. (2015) "Surprising Findings in Three New NEA Reports on the Arts,” Available online at: https://www.arts.gov/news/2015/surprising-findings-threenew-nea-reports-arts.

National Endowment for the Arts (2016), “Arts and Cultural Production Contributed $\$ 704.2$ Billion to the U.S. Economy in 2013,” Available online at: https://www.arts.gov/news/2016/arts-and-cultural-production-contributed-7042-billionus-economy-2013.

Porsse, Alexandre A., Patricia Palermo, and Marcelo Portugal. (2009) "Projeção dos Impactos Econômicos do Natal Luz no Rio Grande do Sul: uma Avaliação a partir do Modelo de Matriz de Insumo-Produto,” Unpublished paper presented at VII Encontro Nacional da Associação Brasileira de Estudos Regionais, São Paulo, Brazil.

Rasmussen, Poul. (1956) Studies in Intersectoral Relations. Amsterdam: North Holland

Reis, Ana. C. F. (2002) Marketing Cultural e Financiamento da Cultura. Thomson Learning.

Reis, Ana. C. F. (2006) Economia da Cultura e Desenvolvimento Sustentável - o Caleidoscópio da cultura. Manole.

Silva, Frederico B., Herton E. Araujo, and Andre L. Souza. (2007) "Emprego formal no setor cultural 1994-2002,” Brasília: IPEA texto para discussão 1276.

Strassert, Günter. (1968-69) “Zur Bestimmung strategischer Sektoren mit Hilfe von Input-OutputModellen,” Jahrbucher fur Nationafikonomie und Statistik, 182, 211-215. 
Souza, G. F., Ana Flavia Machado, and Edson Domingues. (2016) "Economic Impacts of the ValeCultura (Culture Voucher): A Computable General Equilibrium Model," in 19th International Conference on Cultural Economics, Valladolid.

Sonis, Michael and Geoffrey .J.D. Hewings. (1992) “Coefficient Change in Input-Output Models: Theory and Applications,” Economic Systems Research, 4, 143-157.

Towse, Ruth. (2003) A Handbook of Cultural Economics, Edward-Elgar.

Throsby, David. (2004) “Assessing the Impacts of a Cultural Industry,” Journal of Arts Management, Law Society, 34, 188-204.

UNESCO Institute for Statistics (2012) "Measuring the Economic Contribution of Cultural Industries: A Review and Assessment of Current Methodological Approaches,” UNESCO-UIS.

Valiati, Leandro and Stefano Florissi. (2007) Economia da cultura: Bem-estar econômico evolução cultural. Editora da UFRGS.

Vaughan, D.R. (1984) “The Cultural Heritage: An Approach to Analyzing Income and Employment Effects,” Journal of Cultural Economics, 8, 1-36.

Wagner, Odilon. (2016) “É a Cultura, senhores,” O Globo. Available online at: http://oglobo.globo.com/opiniao/e-cultura-senhores-1-19286778.

(C) Southern Regional Science Association 2018. 


\section{APPENDIX}

\section{Appendix 1 - Original 56 Input-Output Sectors in Brazil}

\begin{tabular}{|c|c|c|}
\hline Code & Sector & I-O Code \\
\hline 101 & Agriculture, hunting, forestry & 1 \\
\hline 102 & Livestock and fishing & 2 \\
\hline 201 & Oil and natural gas & 3 \\
\hline 202 & Iron ore & 4 \\
\hline 203 & Other extractive industries & 5 \\
\hline 301 & Food and beverages & 6 \\
\hline 302 & Tobacco products & 7 \\
\hline 303 & Textiles & 8 \\
\hline 304 & textile products & 9 \\
\hline 305 & leather and footwear & 10 \\
\hline 306 & Wood - excludedfurnitures & 11 \\
\hline 307 & Cellulose, paper products & 12 \\
\hline 308 & Journal, Magazines and disks & 13 \\
\hline 309 & Coke, refined Oil product & 14 \\
\hline 310 & Alcohol & 15 \\
\hline 311 & Chemical products & 16 \\
\hline 312 & Manufacture of resin and elastomers & 17 \\
\hline 313 & Pharmaceutical products & 18 \\
\hline 314 & Agrochemicals & 19 \\
\hline 315 & Perfumery and Hygiene products & 20 \\
\hline 316 & Paints, varnishes, lacquers and enamels & 21 \\
\hline 317 & Other chemical products & 22 \\
\hline 318 & Rubber and plastic products & 23 \\
\hline 319 & Cement & 24 \\
\hline 320 & Other non-metallic mineral products & 25 \\
\hline 321 & Steel and steel products & 26 \\
\hline 322 & Non-ferrous metals & 27 \\
\hline 323 & Metallic products, except machines and equipment & 28 \\
\hline 324 & Machines and equipment, including maintenance and repair & 29 \\
\hline 325 & Appliances & 30 \\
\hline 326 & Office, accounting and computing supplies & 31 \\
\hline 327 & Electric machines and devices & 32 \\
\hline 328 & Eletronic and comunication equipment & 33 \\
\hline 329 & Medical and precision optical equipment & 34 \\
\hline 330 & Automotive vehicles & 35 \\
\hline 331 & Trucks and bus & 36 \\
\hline 332 & Parts and accessories for motor vehicles & 37 \\
\hline 333 & Other transport equipment & 38 \\
\hline 334 & Furniture and other products & 39 \\
\hline
\end{tabular}

(c) Southern Regional Science Association 2018. 


\begin{tabular}{rlr}
\multicolumn{2}{c}{ Appendix 1 - Original 56 Input-Output Sectors in Brazilian (Con't) } \\
\hline \hline Code & Sector & I-O Code \\
\hline 401 & Electricity, gas, water, sewage and urban sanitation & 40 \\
501 & Construction & 41 \\
601 & Trade & 42 \\
701 & Transportation, storage and mail & 43 \\
801 & Information service & 44 \\
901 & Finance and insurance & 45 \\
1001 & Real Estate & 46 \\
1101 & Maintenance and repair services & 47 \\
1102 & Accommodation and food services & 48 \\
1103 & Enterprise services & 49 \\
1104 & Private Education & 50 \\
1105 & Private Health & 51 \\
1106 & Community, social and person services & 52 \\
1107 & Households with employed people & 53 \\
1201 & Public Education & 54 \\
1202 & Public Health & 55 \\
1203 & Public Administration and defense & 56 \\
\hline \hline
\end{tabular}

Source: Nereus

Appendix 2 - Cultural Industry-activities for 2005 (CNAE 1.0)

\begin{tabular}{|c|c|c|}
\hline $\begin{array}{l}\text { CNAE } \\
\text { Code }\end{array}$ & Name & $\begin{array}{l}\text { I-O } \\
\text { Code }\end{array}$ \\
\hline 22.21 & Journal, Magazines and books printing & 13 \\
\hline 22.29 & Other graphical services & 13 \\
\hline 22.3 & Reproduction of recorded material & 13 \\
\hline 24.96 & Manufacture of disks and tapes. & 22 \\
\hline 30.21 & Manufacture of computers & 31 \\
\hline 30.22 & $\begin{array}{l}\text { Manufacture of equipment for electronic devices for information } \\
\text { treatment }\end{array}$ & 31 \\
\hline 32.10 & Manufacture of basic electronic material & 33 \\
\hline 32.21 & $\begin{array}{l}\text { Manufacture of equipment for radio and television broadcast and radio } \\
\text { and telephone transmitters. }\end{array}$ & 33 \\
\hline 32.22 & $\begin{array}{l}\text { Manufacture of telephone devices, intercommunication systems and } \\
\text { similar. }\end{array}$ & 33 \\
\hline 32.30 & $\begin{array}{l}\text { Manufacture of radio and television receivers and reproduction, recording } \\
\text { or amplification of sound and video. }\end{array}$ & 33 \\
\hline 33.40 & $\begin{array}{l}\text { Manufacturing of optical devices, instruments and material, and } \\
\text { photographic and cinematographic material. }\end{array}$ & 34 \\
\hline 36.91 & $\begin{array}{l}\text { Stoning of precious and semi-precious stones, manufacture of jewelry } \\
\text { and jewelry artifacts. }\end{array}$ & 39 \\
\hline 36.92 & Manufacture of musical instruments & 39 \\
\hline 36.94 & Manufacture of toys and recreational games & 39 \\
\hline 36.99 & Manufacture of diverse products & 39 \\
\hline
\end{tabular}

Source: IBGE. Note: translation by the authors. 
Appendix 3 - Cultural Industry-activities for 2009 (CNAE 2.0)

\begin{tabular}{lll}
\hline \hline CNAE & & I-O \\
Code & Name & Code \\
\hline 18.11 & Journals, Magazines, books and other periodical publication’s printing & 13 \\
18.21 & Pre-printing servicer & 13 \\
18.22 & Graphic finishing services & 13 \\
18.30 & Reproduction of recorded material & 13 \\
26.10 & Manufacture of electronic components & 33 \\
26.21 & Manufacture of computer equipment & 31 \\
26.22 & Manufacture of peripheral computer equipment. & 31 \\
26.31 & Manufacture of communication transmitters devices. & 33 \\
26.32 & Manufacture of telephone equipment and other communication devices & 33 \\
26.40 & Manufacture of reception, reproduction, recording, audio, and video & 33 \\
& amplification devices. & 34 \\
26.70 & Manufacture of optical, photographic and cinematographic equipment. & 32 \\
26.80 & Manufacture of magnetic, optical and new media. & 39 \\
32.11 & Stoning of gems, manufacturing of jewelry and jewelry artifacts. & 39 \\
32.12 & Manufacture of imitation jewelry and similar items. & 39 \\
32.20 & Manufacture of musical instruments. & 39 \\
32.40 & Manufacture of toys and recreational games. &
\end{tabular}

Appendix 4 - Cultural Service-activities for 2005 and 2009

\begin{tabular}{ll}
\hline \hline I-O Sector & Disaggregated Sector \\
\hline & Travel agency, tour operators and other tourism \\
Services to enterprises & services \\
Services to households & Recreational and cultural activities \\
& Continued teaching activities \\
Information services & Telecommunication \\
& Audio and visual services \\
& Editing and editing integrated to printing \\
& News agencies and other information services \\
& Maintenance and repair of computer and \\
Maintenance and repair services & communication equipment. \\
\hline \hline
\end{tabular}

Source: IBGE. Note: translation by the authors. In 2005 "Editing and editing integrated to printing” was not disaggregated 